\title{
"Language Policy" in Ethiopia: Challenges and Opportunities in Current Trends of Afaan Oromoo
}

\author{
Samuel Leykun ${ }^{1}$, Tamiru Gari ${ }^{2}$ \\ ${ }^{1}$ Department of Linguistics, Ambo University, Ambo, Ethiopia \\ ${ }^{2}$ Department of English Language and Literature, Ambo University, Ambo, Ethiopia
}

Email address:

slekun.leykun455@gmail.com (S. Leykun),tamirugari@gmail.com (T. Gari)

\section{To cite this article:}

Samuel Leykun, Tamiru Gari. "Language Policy" in Ethiopia: Challenges and Opportunities in Current Trends of Afaan Oromoo. Arabic Language, Literature \& Culture. Vol. 5, No. 1, 2020, pp. 1-8. doi: 10.11648/j.allc.20200501.11

Received: November 5, 2019; Accepted: April 20, 2020; Published: April 28, 2020

\begin{abstract}
In many countries, policymakers suspect that the use of local languages in education can result in excessive ethnicization, which may lead to conflicts and divide nations. The objectives of the study are to assess the basic cause that stays Ethiopia to not have its own language policy and to investigate opportunities that leads Ethiopian to have language policy. The subjects of this study are language experts, policy makers and politicians, and target speech community. The major data collection instrument was questionnaire. Interviews with key informants and document analysis were supplementary tools to achieve the objective of the research. To mention some of the findings, a development plan of a country in all aspects should primarily deal with the concrete study of the language issues. There is statistical relationship between measurement and evaluation made by policy makers and opportunities in current trends of Afaan Oromoo (p-0.001). The case of Oromo language is not far from this general perception. Unless this Linguistic right is gained by the Oromo language speakers, these people hardly feel the full citizenship in the entire country, Ethiopia, because they can feel discrimination due to their lack of real participation in the country's overall activities. Such discrimination can even cause conflict at different occasions. As from the general principles of language use is argued, the question of the Oromo language use as a national language is realized, Ethiopia's overall development remain only a wish for the prime reason of lack of Oromo people's motivation in the involvement of political, economic, social activities. Value linguistic and cultural pluralism practically, as demonstrated in the constitution. Currently Ethiopia is in the refolution (reform and revolution) which means education policy, Health policy, foreign relation policy, public service policy, and other major pillars of policies and declarations are changed and/or modified. Therefore, possible to design an independent language policy. Amend the issue of Afaan Oromoo as federal alternative working language in the constitution.
\end{abstract}

Keywords: Language, Policy, Challenges and Opportunities

\section{Introduction}

"Language is the key to communication. It can provide bridges to new opportunities, or build barriers to equality. It connects, disconnects. It creates unity, and can cause conflict. Language is many things, but it is rarely simple."[5]

In multilingual country like Ethiopia multiple official language is advantageous. In Ethiopia "more than 80" languages are spoken. It very tough to know the exact number of languages spoken in Ethiopia that is why most linguist says "more than 80 ". The main reason is that lack of detail study on the Ethiopian languages. The other reason is that the number of languages spoken globally are decreasing dynamically. Every week our world lose one language.
Rather than simply eradicating local knowledge or overwriting it with the official knowledge of the dominant society, it must be acknowledged and employed as the basis of all further learning and development [6]

Different literatures show that Oromo people are the largest ethnic group in Africa. Among the many people living within the borders of present day of Ethiopia the Oromo constitute the most numerous (Bartels 1983: 13). As several sources indicate and the reality exhibits, Oromia is the biggest region in Ethiopia. According to the 2007 Population and Housing Census of Ethiopia, the total population of Oromia National Regional State estimated to 27 million.

In terms of language, Afaan Oromoo is one of the Cushiticspeaking groups of the people living in north east and east 
Africa. Cushitic speakers have inhabited parts of north-eastern and eastern Africa for as long as recorded history. Afaan Oromo and Qubee are currently utilized by the Ethiopian government's state Radio and TV and news paper. Like most Ethiopian languages, whether Semitic or Omotic, Afaan Oromo has a set of ejectives consonants, Afaan Oromo has another glottalized phone that is more unusual, an implosive retroflex stop, /d'/ which is " $\mathrm{dh}$ " in Oromo orthography.

Oromo has the typical southern Cushitic set of five short and five long vowels letters. The difference in the length is contrastive, for example, lafa 'earth' laafaa 'soft'. Germination is also significant in Oromo. That is, consonant gemmination can distinguish words from one another, for example, badaa, meaning 'bad', and baddaa, meaning 'highland. In the Qubee alphabet, a single "letter" consists either of a single symbol or a diagraph (ch, dh, ny, ph, sh) Germination is not required to mark for the diagraphs, though some writers indicate it by doubling the first symbol Laphee 'heart' [8]

Language serves as a tool for sustainable development of a nation in economy, education, science and politics. It also enhances child's cognitive development, social and selfidentity and cultural preservation (Orman, 2008: 116). Moreover, it is used as an instrument and a symbol of power to dominate others (Pattanayak, 2001: 567; Phillipson and Skutnabb-Kangas, 2001: 571; Phillipson, 1988: 339).

According to the study [8], in developing nations, for example, African countries, children have experienced learning through unfamiliar language either the dominant local or a foreign language. In this case, the children whose a language of instruction is not their home language or mother tongue are deterred from using their natural creativity, skills and knowledge that they acquired through language and cultures in their society. As a result, their social and cognitive development that enables them to learn in school is also affected. Their failure in their academic achievement, in turn, contributes to the underdevelopment of their society since they fail to contribute their skills and knowledge to the development of their communities. This means that development in a nation in general and in Africa in particular can be affected by the language factors in education as language, development and education are closely linked [7]

Many authors thus cite the case of Ethiopia as one of the instances where colonial European languages didn't become the official medium of political and social life. Instead, an autochthonous language - i.e. Amharic - assumed the position. However, the fact that Amharic can be considered an autochthonous language in the region, does not make it a less colonial one. What is known in Ethiopia with its current borders which took shape in the 19th century, it is the result of the imperial conquest of the dominant Semitic ethnic group known as Abyssinians (Amharas and Tigreans) and the subjugation of more than 70 different ethnicities living in the country (the most important ones, especially Oromos, coming from Cushitic language family group) during the rule of emperor Menelik II. According to the study [12] following the change of government in 1991, Ethiopia's education system has been undergoing fundamental change. No part of the education system has been left untouched. A centralized administration was replaced by a decentralized one in line with the principle of federalism under which the current government has been organized. The federal Ministry of Education, which was highly centralized in the past, has now been decentralized into many states, district-level bureaus, and departments demarcated on ethnic lines.

The decentralization process, in addition to devolving authority, has brought with it various change initiatives, one of which is the change in media of instruction.

From pedagogical and psychological points of views, educating children through their mother tongue enables them to build their experiences and knowledge about their cultural identity and self-realization. The thing which motivated the researchers to conduct research with this title is that, in Africa, mother tongue and indigenous knowledge is not promoted well and it should be. We Africans, the more we promote our mother tongue in schools, the more we create baseline for economic development, science and technology, true democracy and psychological development. The development of the language is not only using the language in media and schools. With what level and standard Afaan Oromoo is being used in this regard. In addition, what are the hindering factors to consider the target community to use its language at different offices from state to federal levels without any problem? Therefore, this study was conducted to investigate the key challenges and opportunities in current trends of Afaan Oromo in different educational levels and government institutions.

Further more, for the development of Afaan Oromoo, the language needs to get proper social context in which it can be further enhanced. To enhance social context means to pave the way for development of the language in the target community. Besides, the more languages get different social contexts, the better these languages devising strategy in institutionalizing language implementation. In addition, the user of the target language ought to accelerate the use of Afaan Oromoo in different social contexts. For instance, use the language as linguafranca, consider in different media, and etc. Institutionalizing the language can be considered as preserving the language with its wisdom, asset, value, thought and norm for the next generation.

\subsection{Research Problem}

Many scholarly works have so far been dedicated to the study of the various aspects of Oromo history, culture, literature, belief and folklore. However, these scholars have not touched upon the challenges and opportunities in current status of AfaanOromoo. Therefore, this research is going to fill the gap. According to the study [8], in Ethiopia, multilingual policy was launched in the early 1990s after the military regime was toppled. As a result, the previously marginalized languages were recognized and they were allowed to be used in the main domains. The language policy instigated the use of mother tongues in primary education. For instance, the endorsement of the 1994 constitution of Ethiopia supported and adopted the multilingual policy. The 
policy which respected the rights of nations, nationalities and the peoples of Ethiopia was officially implemented. In addition, the constitution, which was stipulated in Article 5, says: (1) All Ethiopian languages shall enjoy equal state recognition, (2) Amharic shall be the working language of the Federal Government and (3) Members of the Federation may by law determine their respective working languages (the Constitution of the Federal Democratic Republic Government of Ethiopia/FDRGE/, 1994).

In Ethiopia to use English as a medium of instruction is indicator of "modernization" and source of "knowledge".

This has its own effect on the cognitive development of the children and the development of local languages. According to Aman (2014), those who argue against the mother tongue use in education claim that since English is used as a medium of instruction in secondary and higher education in Ethiopia, teaching children through their language in primary schools may weaken their proficiency development in English. For this reason, they maintain that teaching children through English from the start enhances their proficiency in English and hence, they have no difficulty learning through the language in secondary education. In other words, their point of argument is that since English is used as a medium of instruction in higher education, teaching them through mother tongue does not help their learning secondary education and it has drawbacks [12].

According to the study [12], at various points in the history of Ethiopia, political motives frustrate any systematic approach to the policy process. For instance, the historic Education Sector Review Program initiated during the early 1970 s to bring fundamental educational reform in the country was aborted before implementation, having been politicized and polarized by opposing political agenda of the stakeholders, which eventually contributed to the fall of the imperial regime in 1974 (Country Studies, 1991). The formulation and implementation process of the current language policy is also a typical victim of this inadvertent trend. Soon after the EPRDF took over as a transitional government in 1991, it convened a Conference for Peace and Democracy in Addis Ababa from July 2-6, 1991 [1]. The conference, among other things, issued a policy guideline for the immediate provision of primary school instruction in five major ethnic languages. In addition to this, a decision was reached to allow choices of scripts in which the languages were to be written. Accordingly, the Latin alphabet replaced the Ethiopic alphabet for the Cushitic languages (which host most of the minority language groups) and the Ethiopic alphabet was retained for the Semitic language groups.

According to the study [1], Ethiopia, as one of the multilingual and multicultural countries, has faced the critical problem of development and implementation of language use policy that could satisfy the needs of various societies in question and contribute to their socioeconomic and sociocultural development.

On the other hand, scholars argued that nations that run well-planned and well-implemented mother-tongue education or mother tongue-based, bilingual/multilingual programs would gradually reduce ethnic conflict [12]. They have the view that the inclusion of the use of people's languages in the main domains is their natural and legitimate rights. In this sense, they feel a sense of belonging in the national affairs if their right to use their language in the main domain is respected and included. This research can be considered as a baseline study.

\subsection{Objectives of the Study}

\subsubsection{General Objective}

The general objective of this study is to investigate the challenges and opportunities in Current Trends of Afaan Oromoo from language policy and implementation perspectives.

\subsubsection{Specific Objectives of the Study}

The specific objectives of this study are:

1. To investigate the major problems of Ethiopian language policy both at policy level and implementation level.

2. To investigate opportunities in Ethiopian language policy in relation to the current trends of Afaan Oromo.

3. To explore the opportunities in Ethiopian language policy in relation to current trends of Afaan Oromoo.

\subsubsection{Research Questions}

In the course of the research, the study was answer the following research questions:

1. What are the major language policy problems in Ethiopian?

2. What are the challenges of language policy in current trends of Afaan Oromoo?

3. What are the opportunities in Ethiopian language policy in current trends of Afaan Oromoo?

\subsection{Rationale of the Study}

This research was one of the systematic research attempts to investigate Language Policy in Ethiopia: challenges and Opportunities in Current Trends of Afaan Oromoo.

Thus, this study was come up with new findings, conceptual frameworks, and implementation strategies for language policy and planning to alleviate obstacles that have been affecting language policy in the target language. The expected findings were also important for the Oromia Education Bureau, Oromia Culture and Tourism Bureau, the Regional State of Oromia and for the native speakers of the language. Thus, the findings was noteworthy for the next reasons: they are imperative to outline policy recommendations that are relevant to Ethiopian language policy or African language policy, the policy implications was drawn from the findings of this study, they can provide the need for reliable information on which the language policy development must be based and lastly, they can provide some information to other researchers who need to conduct further research in the area. 


\section{Materials and Methods}

This study needs its own methodology in order to achieve its purposes. The methodology: the data collection instrument, the data gathering procedures, the data analysis techniques etc has the following components and procedures. This research basically uses quantitative and qualitative (mixed) methods.

\subsection{The Study Subject}

The study was carried on language teachers at different levels, language experts, policy makers and politicians, target speech community and all stakeholders. The numbers of the study population is supposed to exceed 40 millions. But the sample population is limited to 200 primary school students, 20 primary school language teachers of different levels, 16 primary school principals, 5 language policy makers, 7 linguists, 15 target speech community and 7 politicians.

\subsection{Techniques of Sampling}

For this study the researcher was use a purposive sampling. In this study, knowledgeable individuals were considered. The researcher was stick to informants whom he believes that they were given him ample information. It enables the researcher to increase the external validity that refers to the generalisability of results from quantitative study to other population, settings, times and others. The purposive sampling was used to increase the transferability which refers to the generalisability of results from one specific sending context in qualitative study to another particular receiving context [7]. Purposive sampling technique was preferred by the researcher believes that since the subjects of the research are language teachers, target speech community, language policy makers, and politicians.

\subsection{Methods of Data Collection}

The major data collection instrument was questionnaire. Interviews with key informants and document analysis were supplementary tools to achieve the objective of the research.

\subsection{Questionnaire}

A questionnaire were helped the researcher to gather information from a large number of respondents. It has a diversified nature used for different reasons depending on their purposes, size, appearance and/or the way they are administered. With this research the questionnaire was distributed to different subjects of the study (language teachers at different education level, students, school principals, curruculum designers, and language policy makers). Further more, in this study questionnaire was prepared and distributed to respective informants. Questionnaire has advantages for the researcher to gather reliable and valid data. It is economical, in a sense that it can supply a considerable amount of research data for a relatively low cost in terms of materials, money and time, and it is also easier to arrange (Denscombe, 2007: 169

\subsection{Interview}

An interview is one of the major research tools which were used to collect straightforward information in a real situation through conversations that take place between an interviewer and a number of interviewees. After the researcher designed different interview questions, the researcher were interviewed school language teachers, linguists, language policy makers and politicians. In order to investigate possible information from the interviewee, an interview is worthwhile to obtain information from the respondents. It plays a profoundly significant role to deal with complex behaviors of people in order to obtain the possible facts from the interviewee.

\subsection{Document Analysis}

Document analysis was used as a part of this study. The documents are textbooks, constitution of the country, report or proclamation on language issue by state administration or federal government, report of regional education bureau, research findings on international journals and the like.

\subsection{Techniques of Data Analysis}

The data was analyzed qualitatively and quantitatively. The quantitative data which was collected through questionnaire was analyzed using SPSS. Whereas, the data collected through interview and document analysis was analyzed using narrative and content analysis.

\section{Results and Discussion}

This part contains the data analysis and discussions using different tools (interview, questionar and document analysis).

\subsection{Analysis of Data Obtained Through Interview}

This sectionpresents data analysis and discussions collected using an interview. According the data were collected from language teachers, linguists, language policy makers and politicians.

Interview with IT1

Researcher: What do you think of multiple national languages in Ethiopia?

Informant: In my opinion, Afan Oromo should be the official or working language of the country. There are linguistic and non-linguistic rationales for this assertion. The linguistic reason stems from the language's (Afan Oromo) rich literacy tradition. The literacy riches of the Oromo people are embedded in the Afan Oromo. The variety of stories, proverbs, and other traditions reflected the social, political, and psychological life of the Oromo society. These literacy traditions of the people are generally well documented in various times.

Afan Oromo has been used for all cycles of education (primary, secondary and precollege) in Oromia region for more than two decades. It has become a good example of mother tongue education in the region as it believed that learning in mother tongue for students to learn indigenous knowledge, easily understand the subject and contextualize 
the examples. It also enables students to be aware of their own society.

I think the rich literacy traditions of the Oromo society should be learned and be used by other Ethiopian people. As there are traditions commonly shared by all Ethiopians, there are also traditions peculiar to the Oromo society. Other Ethiopian people could be benefited from this wisdom of the Oromo people.

Making Afan Oromo an official or working language along with Amharic also has a political significance. This is because Afan Oromo is spoken in Oromia region which is the largest in Ethiopia. The language is also spoken in Amhara region in a zonal level. There are also small portion of people in Tigray region speaking Afan Oromo. These examples indicate the language is not confined to the Oromia region. Since, Oromo are the single largest linguistic group in Ethiopia, making the Afan Oromo the official language would help in strengthening the unity and solidarity in the country.

Interview with IT2

Researcher: What do you think of multiple national languages in Ethiopia?

Informant: Make use of Afaan Oromoo as a federal language has a tremendous advantage for native and nonnative speakers of the language. Some of the advantages are:

1. Assure that any language can be a federal working language when meets the criteria,

2. Explicitly states the role of language in development,

3. Based on the rule of law this can be considered as a pavement of the way for linguistic right.

4. Language option for the users at federal level,

5. Create an opportunity for being a bilingual and/or multilingual,

6. Increase respect, true love, and unity with other ethnic groups.

7. Save time and money which means no need to use interpreter for any kind of social affairs by the target community, and

8. Above all political stability in the country.

9. Afan Oromo is a linguafranca in Ethiopia of different regions:

a) At Benishangul GumuzMatakal Zone,

b) At Region Gambellaa (including Ethio-sudan border),

c) At SNNP Region,

d) At Tigray Region Rayyaa,

e) At Afar region,

f) At Ethio-Somalia Region,

g) At Amhara Region WelloKemise Zone,

h) At Harari Region, and

i) At border of almost all regions in the country.

10. At continent level spoken in Kenya, Somalia, and the third largest language in Africa.

Interview with IT3

Researcher: What do you think of multiple national languages in Ethiopia?

Informant: Oromo people and other Ethiopian citizens, if Afan Oromo becomes national language

The role of a language in a country is of great importance.
Therefore, it needs serious concern. As a language is human and thereby human is generative power for the development of a country; language issues must be studied and given a justifiable decision before all other that needs discussion. A development plan of a country in all aspects should primarily deal with the concrete study of the language issues. Open discussion should be done with its speech community. The case of Oromo language is not far from this general perception.

The following are some of the common understanding of benefits if Afan Oromo becomes a national language of Ethiopia.

Democratic system is realized in the country, because it is human right to use their languages at all levels as these actual language uses facilitate human's utilization of all the resources around them. These resources can include social capital- culture such as philosophy, value system, norm, attitude, belief, etc. These can be perceived as knowledge which is decisive for using natural resources which includes wide range of land, water, forest animals and minerals. Resources for improvement of the community's life standard are more accessed if the beneficiaries use their indigenous languages which are still achieved by their mother tongue.

Unless this democratic right is gained by the Oromo language speakers, these people hardly feel the full citizenship in the entire country, Ethiopia, because they can feel discrimination due to their lack of real participation in the country's overall activities. Such discrimination can even cause conflict at different occasions. This in turn can violate the democratic principle which the modern politics in $21 \mathrm{st}$ century's society recommends. It is obvious that unless every ethnic group realizes their language use which is expected at all levels which include national language use, it is not thought of country's development.

As from the general principles of language use is argued in the above paragraphs, the question of the Oromo language use as a national language is realized, Ethiopia's overall development remain only a wish for the prime reason of lack of Oromo people's motivation in the involvement of political, economic, social activities. Other specific reasons can be brought front. As can be observed, the current generation, Oromo generation hardly speaks Amharic language, the present national language; they cannot share the federal level positions in all sectors of the country's activities. Though acceptance of this outlook temporally seems to be hard some, it is an absolute solution for sustainable peace and unity among all ethnic groups in Ethiopia.

Basically, the usage of alternative language as a national language has many advantages; for it is potential for accessing government policies and strategies, thereby helping involving the people of that language. The new technological terms that are regularly invented, for instance, agricultural innovations, people possibly can more easily understand than their second language, though this can be worse when it is in the foreign language, such as English. Moreover, the importance of alternative national language can be applicable in the case of other agricultural inputs such as pesticides and fertilizers, because the beneficiaries can read and understand 
the usage of these provisions.

The other critical issues that can be useful when second national language is permitted, it creates alternative language learning need for the former only national language speakers. These opportunities help the other citizens they learn others' cultural, and social capitals which in turn enables them not only imposing others to learn their language but also learn from others. This argument can indicate that winning others by approving their values. These keeps the mutual existence of the different ethnic groups.

The refusal of accepting other language for being alternative national language can arises from the perception that it can dominate oneself language, but the reality can be the reverse in that it can positive competition among the competitive languages for either can develop their own language for showing their artistic values on cultural shows.

The more language of the target community develop, the better that language is easily accessed by L2. This has its own advantage in creating strong social bondage among different language speaker. Besides, the number of linguafranca is also increase. In addition, the speaker of the target community highly motivated to use their language where ever they go at any government offices. More over the target community want to use their own language regardless of social affairs limitation.

There are two main criteria: Linguistic criteria and nonlinguistic criteria. To mention some of the linguistic criteria: number of the target language speaker, standardization of the target language (language of education, media, technology and etc), whether other native use the target language as linguafranca (language which used for market purpose, buying and selling goods). Non-linguistic criteria are good will of the government, and etc. Here it is better to raise the issue of Afaan Oromoo, it is possible to conclude that Afaan Oromoo can meet linguistic criteria as mentioned above. Unless as stated above by well known linguists Elwert, 2001, Wolff 2004, systematically exclude the use of the majority's vernacular languages can no longer be justified by political leaders.

\subsection{Analysis of Students' Response to the Questionnaire}

The questionnaire part presented for the students were contain only close-ended questions. More explicitly, for the close-ended questions the researchers applied SPSS to analyze thoroughly. In the SPSS analysis frequency, average, and statistical relationship between the variables, has been assessed critically.

Table 1. Responses of students.

\begin{tabular}{|c|c|c|c|}
\hline \multirow{2}{*}{ Variables } & \multirow{2}{*}{ Category } & \multirow{2}{*}{ Percent } & \multirow{2}{*}{$\begin{array}{l}\text { Significance } \\
\text { Chi-square (Sig.) }\end{array}$} \\
\hline & & & \\
\hline \multirow{4}{*}{ Age } & $5-15$ years & $66 \%$ & \multirow{4}{*}{0.18} \\
\hline & $16-20$ years & $30 \%$ & \\
\hline & $21-25$ years & $4 \%$ & \\
\hline & Above 26 year & $0 \%$ & \\
\hline \multirow{2}{*}{ Grade level } & $5-6$ grade & $6.2 \%$ & \multirow{2}{*}{0.21} \\
\hline & $7-8$ grade & $93.8 \%$ & \\
\hline \multirow{5}{*}{ Education Level of the family } & TTI & $1.8 \%$ & \multirow{5}{*}{0.001} \\
\hline & Digree & $28.6 \%$ & \\
\hline & Second digree & $4.5 \%$ & \\
\hline & $\mathrm{PhD}$ & $0.9 \%$ & \\
\hline & Other & $64.3 \%$ & \\
\hline \multirow{4}{*}{ Favorite Subject of the Students } & Language & $27 \%$ & \multirow{4}{*}{0.001} \\
\hline & Social Science & $7 \%$ & \\
\hline & Mathematics & $33 \%$ & \\
\hline & Natural science & $33 \%$ & \\
\hline \multirow{5}{*}{$\begin{array}{l}\text { The learning and teaching process takes place in my } \\
\text { education level is very satisfactory. }\end{array}$} & S. Agree & $0 \%$ & \multirow{5}{*}{0.002} \\
\hline & Agree & $2 \%$ & \\
\hline & N. D & $10 \%$ & \\
\hline & Disagree & $30 \%$ & \\
\hline & S. Disagree & $58 \%$ & \\
\hline \multirow{6}{*}{$\begin{array}{l}\text { There is proper policy implementation in current } \\
\text { trends of AfaanOromoo. }\end{array}$} & S. Agree & $0 \%$ & \multirow{5}{*}{0.002} \\
\hline & Agree & $0 \%$ & \\
\hline & N. D & $2 \%$ & \\
\hline & Disagree & 36 & \\
\hline & S. Disagree & $62 \%$ & \\
\hline & S. Agree & $71 \%$ & \multirow{5}{*}{0.001} \\
\hline \multirow{4}{*}{$\begin{array}{l}\text { Increase social contexts in AfaanOromoo can play its } \\
\text { role in the standardization of AfaanOromoo }\end{array}$} & Agree & $27 \%$ & \\
\hline & N. D & $2 \%$ & \\
\hline & Disagree & $0 \%$ & \\
\hline & S. Disagree & $0 \%$ & \\
\hline \multirow{5}{*}{$\begin{array}{l}\text { There is (are) challenges while implementing } \\
\text { language practices in education in schools. }\end{array}$} & S. Agree & $85 \%$ & \multirow{5}{*}{0.002} \\
\hline & Agree & $12 \%$ & \\
\hline & N. D & $3 \%$ & \\
\hline & Disagree & $0 \%$ & \\
\hline & S. Disagree & $0 \%$ & \\
\hline
\end{tabular}




\begin{tabular}{|c|c|c|c|}
\hline \multirow{2}{*}{ Variables } & \multirow{2}{*}{ Category } & \multirow{2}{*}{ Percent } & Significance \\
\hline & & & Chi-square (Sig.) \\
\hline \multirow{6}{*}{ Policy implementation is part and parcel of policy } & S. Agree & $75 \%$ & \multirow{6}{*}{0.0012} \\
\hline & Agree & $23 \%$ & \\
\hline & N. D & $2 \%$ & \\
\hline & Disagree & $0 \%$ & \\
\hline & S. Disagree & $0 \%$ & \\
\hline & S. Agree & $0 \%$ & \\
\hline \multirow{3}{*}{$\begin{array}{l}\text { Language policy maker are evaluate, Coach, monitor, } \\
\text { follow up and take feedback the implementation of } \\
\text { language policy. }\end{array}$} & N. D & $10 \%$ & \multirow[t]{3}{*}{0.001} \\
\hline & Disagree & $30 \%$ & \\
\hline & S. Disagree & $60 \%$ & \\
\hline \multirow{4}{*}{$\begin{array}{l}\text { There are numerous opportunities in current trends of } \\
\text { Afaan Oromoo. }\end{array}$} & S. Agree & $80 \%$ & \multirow{4}{*}{0.191} \\
\hline & Agree & $20 \%$ & \\
\hline & N. D & $0 \%$ & \\
\hline & Disagree & $0 \%$ & \\
\hline
\end{tabular}

The above table reveals that, the age of most students are 5-15 (66\%). 16-20 (30\%) and the rest 21-24 (4.\%). On the other hand, according to the above table, the grade level of most students is 7-8. More explicitly, the data were collected from students using questionnaire from students with grade between 5-6 (6.2\%) and 7-8 (93.8\%).

According to the above table, out of 200 students the favorite subject of $54(27 \%)$ students is language. On the other hand the favorite subject of $14(7 \%)$ students is social science. In addition the favorite subject of $66(33 \%)$ students is Mathematics. More over the, 66 (33\%) prefer natural sciences.

Being asked whether learning and teaching process takes place in education is very satisfactory or not. The above table reveals that, out of 200 students $116(58 \%)$ responded that strongly disagree, 60 (30\%) responded disagree, $20(10 \%)$ responded not decided and $4(2 \%)$ responded agree. In addition, there is statistical relationship between learning and teaching process takes place in education and opportunities in current trends of Afaan Oromoo (p-0.002).

The above table shows that, $142(71 \%)$ responded that strongly agree, $72(36 \%)$ responded that disagree and $4(2 \%)$ responded that not decided whether the policy is properly implementated in current trends of Afaan Oromoo. Moreover, there is statistical relationship between policy is properly implementated in current trends of Afaan Oromoo and an opportunities in current trends of Afaan Oromoo (p-0.002).

According to the above table, 124 (62\%) responded that strongly disagree, $54(27 \%)$ responded that agree and $4(2 \%)$ responded that not decided being asked increase social contexts in Afaan Oromoo can play its role in the standardization of Afaan Oromoo. Besides, there is statistical relationship between increase social contexts in Afaan Oromoo can play its role in the standardization of Afaan Oromoo and an opportunities in current trends of Afaan Oromoo (p-0.001).

Being asked there is (are) challenges while implementing language practices in education in schools. The above table reveals that, out of 200 students $170(85 \%)$ responded that strongly agree, $24(12 \%)$ responded agree, $6(3 \%)$ responded not decided. In addition, there is statistical relationship between challenges while implementing language practices in education in schools and an opportunities in current trends of AfaanOromoo (p-0.002).

The above shows that, $150(75 \%)$ responded that, strongly agree, $46(23 \%)$ responded that agree, and $4(2 \%)$ responded that nor decided whether Policy implementation is part and parcel of policy or not. Besides, there is statistical relationship between Policy implementation is part and parcel of policy and an opportunities in current trends of Afaan Oromoo (p-0.0012).

According to the above table, 120 (60\%) responded that, strongly disagree, $60(30 \%)$ disagree, $20(10 \%)$ responded that not decided being asked Language policy maker are evaluate, Coach, monitor, follow up and take feedback the implementation of language policy. Besides, there is statistical relationship between Language policy maker are evaluate, Coach, monitor, follow up and take feedback the implementation of language policy and an opportunities in current trends of Afaan Oromoo (p-0.001).

The above table shows that, out of 200 students $160(80 \%)$ responded that strongly agree, $40(20 \%)$ responded agree, being asked there are numerous opportunities in current trends of Afaan Oromoo.

\section{Conclusion and Recommendation}

1. The current endorsed language policy should promote multilingualism. And encourage genuinely the multiple national langauges at federal offices.

2. Value linguistic and cultural pluralism practically, as demonstrated in the constitution.

3. Multiple national Languages should be encouraged at country level.

4. For a multi-lingual country like Ethiopia, independent language policy document must be designed and publicized to Ethiopians.

5. The issues of multiple national languages or using many languages at federal offices should be part of native speakers right (not for political advantage/ political concussion).

6. In mullti-lingual countries the issue of multiple national languages or using many languages at federal offices is just a linguistic right.

7. Above all multiple national languages or using many 
languages at federal offices should be considered as creating harmony among the nations and nationalities of Ethiopia.

8. The half wing of language policy is implemented at school. Therefore, schools in particular and education sectors in general should work closely in promoting multiple national language.

9. Set explicit criteria in which other Ethiopian languages can be considered at different offices beyond regional level.

10.Amend the issue of Afaan Oromoo as federal working language in the constitution.

11. To create a true national unity and prevent inter-ethnic conflicts, Ethiopia must promote multiple official language and multilingualism.

12. To create harmony among nation and nationalities, Ethiopia should encourage multiple official language and multilingualism.

13. To create ethno-nationalism and ethio-nationalism, Ethiopia ought to promote multiple national language policy.

\section{Acknowledgements}

Our special thank goes to all our informants who were take part in this study directly. We would also express our gratitude to Ambo University for providing us with finance and vehicle in which it was very tough to conduct this research.

\section{References}

[1] Burton L (2013) Mother Tongue-Based Multilingual Education in the Philippines: Studying Top-Down Policy Implementation from the Bottom Up: Un published PhD Dirertation, Presented at UNIVERSITY OF MINNESOTA.

[2] Chiatoh, B. (2005) Language, education and development. ADEA Newsletter. Volume 17, Number 2. Retrieved from $\mathrm{http} / / /$ www.adeanet.org/sites/default/files/v17n2_eng_web.pdf.
[3] Chiuye G. and Moyo T. (2008) Mother-tongue education in primary schools in Malawi: From policy to implementation: S. Afr. J. Afr. Lang., 2008, 2.

[4] Cohen, Gideon PE, (2008) Mother Tongue and Other Tongue in Primary Education: Can Equity be achieved with the use of different languages?

[5] Kosonen, K. \& Young, C. (eds) (2009) Mother Tongue as a Bridge Language of Instruction: Policies and Experiences in Southeast Asia. Bangkok: Southeast Asian Ministers of Education Organization (SEAMEO).

[6] Kosonen, K., Person, K., Phongsathorn, V., Young, C., Bista, M. \& Bang, K. (2013) MTB MLE. Mother TongueBased Multilingual Education. Lessons Learned from a Decade of Research and Practice. Multilingual Education Working Group Asia-Pacific. Presentations and discussions at the 4th International Conference on Language and Education, 'Multilingual Education for All in Asia and the Pacific: Policies, Practices and Processes', held in Bangkok, Thailand in November 2013. Retrieved from http://www.unescobkk.org/fileadmin/user_upload/library/edoc uments/MTBMLE_23_Oct.pd.

[7] Ouane, A. (2005) Learning, but in which language? Editorial. ADEA Newsletter. Volume 17, Number 2. Retrieved from http://www.adeanet.org/sites/default/files/v17n2_eng_web.pdf.

[8] Samuel L., and Wolde E.,(2015),'Linguistic Analysis of Moribund Lexicons: Focus on Baalee Oromo', Journal of Science and sustainable Development (JSSD), VOLUME 2 ISSUE 1, 73-85.

[9] Samuel L., and Wolde E., (2017) 'Critical Analysis of the Diacritic /'/ inAfan Oromo', Ethiopian Journal of Social and Language Studies, Vol. 4 No. 1.

[10] Samuel L. (2019). Assesment of mother toungue education at primary schools: West Shoa in focus (unpublished research).

[11] Sandberg A (2017). Mother Tongue-Based Multilingual Education Among Linguistic Minorities, Indira Helsinki.

[12] Yonathan A.(2014) Multilingual Language Policy And Language Practice In Ethiopia: Opportunities And Challenges For National Unity And Development, unpublished PhD Dissertation presented at Addis Ababa University. 